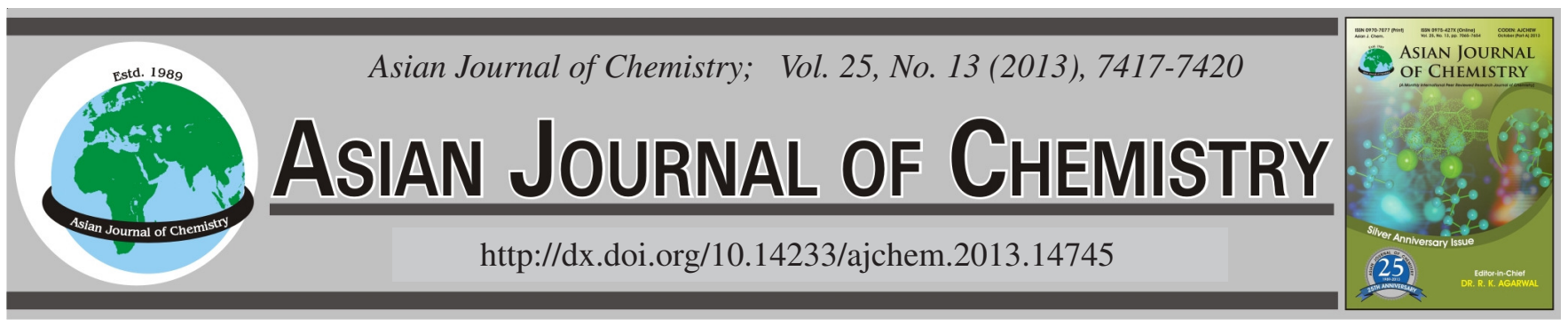

\title{
Atomic Absorption Spectrophotometric Determination of Trace Amounts of Arsenic and Some Heavy Metals in Their Treatment Technology by Iron Powder
}

\author{
Pham Thi Kim Giang ${ }^{1, *}$, Dang Xuan Thu ${ }^{2}$ and Ho Viet QuY ${ }^{2}$
}

${ }^{1}$ Department of Natural Sciences, Hung Vuong University, Campus 1: Nong Trang Ward, Viet Tri City, Phu Tho Provice, Vietnam
${ }^{2}$ Faculty of Chemistry, Hanoi National University of Education, 136 Xuan Thuy Street-Cau Giay District, Hanoi, Vietnam

*Corresponding author: E-mail: tranchunghhvl@gmail.com; kimgiang0378@gmail.com

(Received: 30 October 2012;

Accepted: 29 June 2013)

AJC-13719

\begin{abstract}
Arsenic and heavy metals present in wastewater were determined before and after treatment on the adsorbent column is significant science in Vietnam. In this study, we used the available natural materials, it is powdered and $\mathrm{Fe}^{(0)}$ yellow sand, $\mathrm{MnO}_{2}$ powder under the granules used as adsorbent in the column. The survey materials were examined by X-ray diffraction (XRD), scanning electron microscopy (SEM). These study showed that the material consists of magnetite $\mathrm{Fe}_{3} \mathrm{O}_{4} 38.18 \%$, hematite $\mathrm{Fe}_{2} \mathrm{O}_{3} 12.73 \%$, wuestite $\mathrm{FeO} 16.36 \%$ of the beneficial minerals for the adsorption of heavy metals. The results showed that the material can remove As and some heavy metals out of the environment, in particular: arsenic adsorption capacity $(169.65 \mathrm{mg} / \mathrm{kg}$ ) and some metals such as $\mathrm{Mn}, \mathrm{Fe}, \mathrm{Cu}, \mathrm{Pb}, \mathrm{Cd}$, respectively: $6616.05,6664.24,426.07,143.06$ and $120.21 \mathrm{mg} / \mathrm{kg}$ and maintained for a period of 4 days. This shows good potential applications of sand and iron powder $\mathrm{Fe}^{(0)}$ in the treatment of heavy metal pollution by column adsorption method.
\end{abstract}

Key Words: Arsenic, Heavy metals, Iron powder.

\section{INTRODUCTION}

Water pollution problems are the global concerns, especially pollution of arsenic and heavy metals ${ }^{1,2}$. In Vietnam water is seriously contaminated by the amount of heavy metals ${ }^{3-5}$. The delivering the measures to reduce pollution is necessary and urgent ${ }^{6}$. In particular, with some low developed economic regions, this pollution is an agony problem ${ }^{7}$. It has been existing for a long time, but the pollution is not properly concerned ${ }^{7,8}$. Until the consequences left a large number of fatal diseases which claimed many human lives, the people now realizing about environmental issues and the impacts of environmental public health ${ }^{4,9-11}$. Because the environmental pollution causes some incurable diseases such as cancer, tuberculosis, etc., until now there is no medical treatment effective ${ }^{12,13}$. Arsenic and heavy metals pollution is also one of the causes of these diseases $^{2}$. Therefore, we conducted the research in analyzing amount of arsenic and some heavy metals by atomic absorption spectrophotometry (AAS) method and initial treatment of metal contaminated in polluted water by iron powder to provide model of wastewater treatment.

\section{EXPERIMENTAL}

The As(V), Cd(II), Cu(II), Mn(II), Pb(II), Fe(III) solutions were prepared by the standard solutions (1000 ppm) of Merck
(Germany) production. All research solutions were prepared in volumetric flasks which have been checked volume precision manufacturing by Merck Company of Germany. Studied solutions have been diluted to concentration about $10^{-8}$ to $10^{-6} \mathrm{M}$ and used for a short period of time that not exceeding three days. The $\mathrm{HCl}, \mathrm{HNO}_{3}, \mathrm{H}_{2} \mathrm{SO}_{4}$ solutions were all produced by Merck Company in Germany. Using twice distilled water was distilled in Hamilton machine produced in Britain.

The measurements were performed on atomic absorption spectrophotometer Shimadzu 6300 made in Japan. Material ( $80 \mathrm{~g}$ ) of constant weight is stuffed into plastic columns with a capacity of $60 \mathrm{~mL}$ (disposable plastic syringe). The research solution was prepared from the standard solutions, put in a treatment vessels. This vessels have control valve to have a constant flow rate of $5 \mathrm{~mL} / \mathrm{min}$. Conduct experiments continuously and sample flow continuously during the study period. Sample taken is tested by the test kit in the same day, then take measurements on atomic absorption spectrometer to determine the total arsenic content and other metal ions remaining in the water before and after treated through the column. In order to check the accuracy of the Shimadzu 6300 machine, we conducted measurement with one standard sample on a Shimadzu 6800 in a different laboratory and having results matching between two machines (relative error less than $15 \%$ ). 
Experimental conditions: After research, the optimal conditions are surveyed to identify some heavy metals on Shimadzu 6300 spectrometer, survey the acid background for each metal, plot the standard curve elements $\mathrm{Cd}(\mathrm{II}), \mathrm{Cu}(\mathrm{II})$, $\mathrm{Mn}(\mathrm{II}), \mathrm{Pb}$ (II), $\mathrm{Fe}$ (III) by the flame atomic absorption spectrophotometric method. As(V) and As(III) are studied in similar way and surveyed by non-flame atomic absorption spectrophotometry (graphite furnace).

For arsenic, we have the conditions surveyed in this equipment by furnace graphite with parameters of wavelength: 193.7 $\mathrm{nm}$, HCL intensity $12 \mathrm{~mA}$, slit width $7 \mathrm{~nm}$. Parameters of Furnace graphite for measurement: drying temperature in steps $1,2,3$ are at $150^{\circ} \mathrm{C}$ during $20 \mathrm{~s}, 250^{\circ} \mathrm{C}$ during $10 \mathrm{~s}, 600^{\circ} \mathrm{C}$ during $10 \mathrm{~s}$, respectively and ashing temperature in step 1 is $600{ }^{\circ} \mathrm{C}$ for $10 \mathrm{~s}$, step 2 is $600^{\circ} \mathrm{C}$ for $3 \mathrm{~s}$. Temperature of atomization is in $2200{ }^{\circ} \mathrm{C}$ for $2 \mathrm{~s}$ and cuvette is cleaned for $2 \mathrm{~s}$ at $2500^{\circ} \mathrm{C}$. Determination arsenic in linear range: $2-80 \mathrm{ppb}$.

Wastewater treatmental technology by iron powder: We present the results of application materials available in nature for the treatment by the column adsorption experiments of arsenic and heavy metal pollution polluted water such as: $\mathrm{Cd}(\mathrm{II}), \mathrm{Cu}(\mathrm{II}), \mathrm{Mn}(\mathrm{II}), \mathrm{Pb}(\mathrm{II}), \mathrm{Fe}(\mathrm{III})$. Using a scanning electron microscope (SEM) on a GEOL 6490 made in Japan (Institute of Materials Science) and X-ray fluorescence analysis (XRD) on a Siemens D5005 in Faculty of Physics, HUS-VNU to investigate the original material before conducting the experiment shown in Figs. 1 and 2, respectively. Fig. 1 showed that the surface area is different with particle size from 14.45$31.80 \mu \mathrm{m}$.
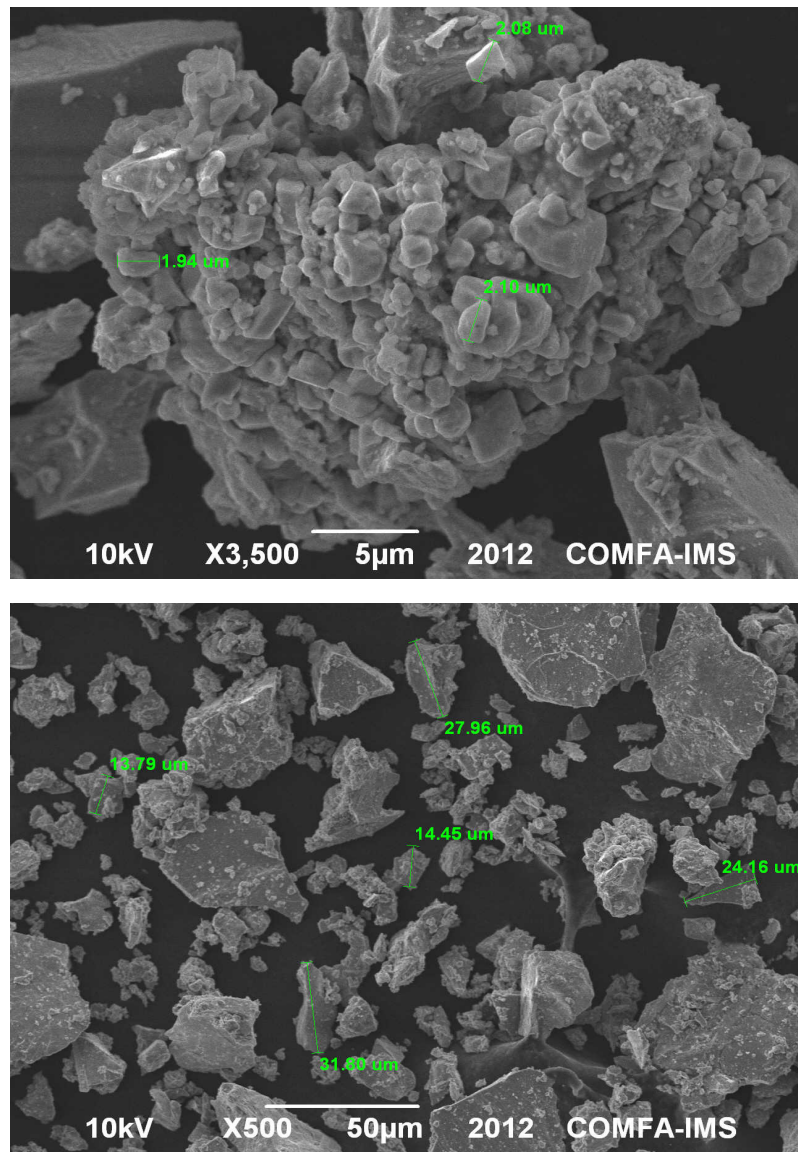

Fig. 1. SEM graph of iron powder material samples

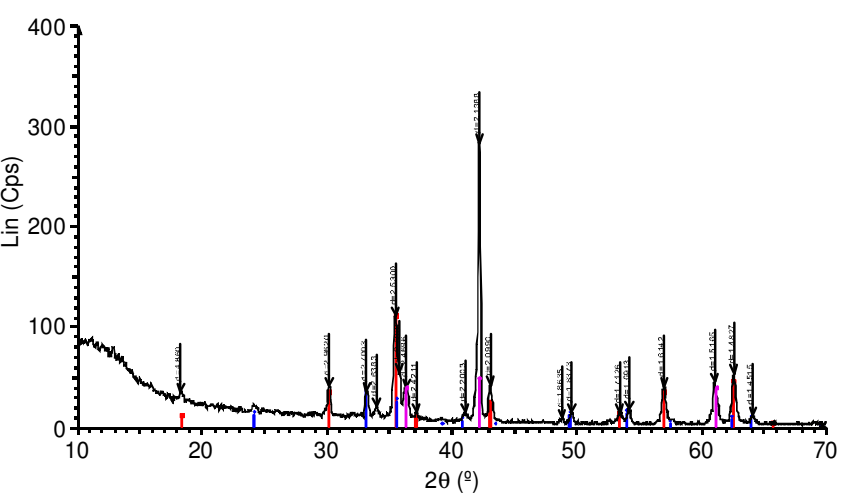

Fig. 2. Spectrum schematic analysis results of Fe powder materials by XRD method

The results show that adsorptive material $\mathrm{Fe}(0)$ including magnetite $\mathrm{Fe}_{3} \mathrm{O}_{4} 38.18 \%$, hematite $\mathrm{Fe}_{2} \mathrm{O}_{3} 12.73 \%$, wustite $\mathrm{FeO} 16.36 \%$ is a suitabe mineral for the adsorption of heavy metals.

Preparation of the column of material: Components of material are iron powder sold on the market and natural sand and soaked and washed carefully twice with distilled water. Using the original standard solution of $\mathrm{As}(\mathrm{V}), \mathrm{As}(\mathrm{III})$ and metal ions: $\mathrm{Cd}(\mathrm{II}), \mathrm{Cu}(\mathrm{II}), \mathrm{Mn}(\mathrm{II}), \mathrm{Pb}(\mathrm{II}), \mathrm{Fe}(\mathrm{III})$ prepared from the stock solutions with concentration of 1000 ppm Merck Company in Germany to dilute into the concentrations closed to the actual wastewater samples to conduct experiments adsorption in column. $\mathrm{pH}$ is the same with the $\mathrm{pH}$ of wastewater samples of the environment. In this experiments, ion forces at $\mathrm{I}=0.01 \mathrm{M}$ were adjusted by $\mathrm{NaNO}_{3}$ salt solution to keep the ion forces similar to the natural environment sampleds. The industrial wastewaters were collected from Lam Thao Chemical factory, discharged into the environment through the sewage system containing elements in excess of permission standard. Treatment procedure: In this study, the adsorption column made of (disposable) plastic syringe with a volume of $60 \mathrm{~mL}$ is inserted by $80 \mathrm{~g}$ of the material particles including yellow sand and black sand washed several times with twice distilled water and mixed with iron powder with the proportion with 2 , 5 and $10 \%$ Fe in weight, respectively, at a constant height and flow from the top to down through the clean plastic container system with controlling valve to have the flow constant rate ca. of $5 \mathrm{~mL} / \mathrm{min}$.

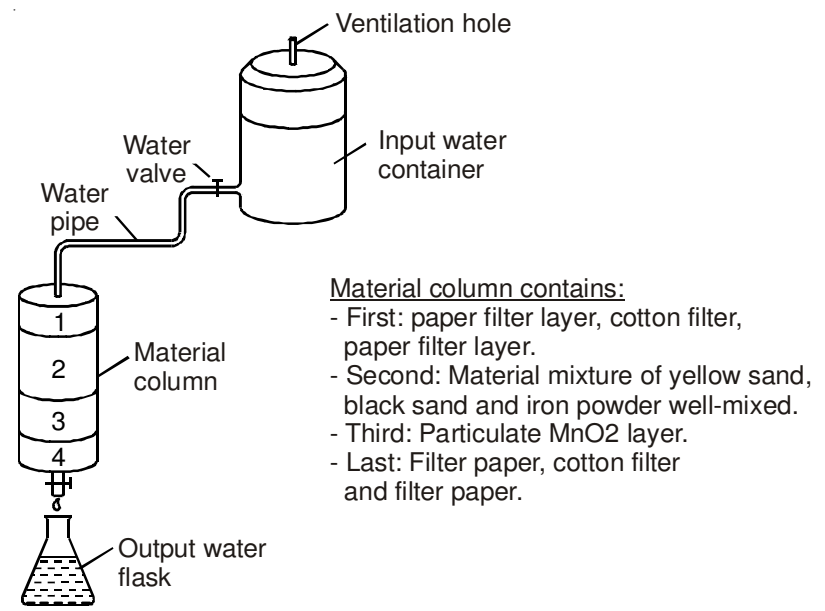

Fig. 3. Model diagram of water treatment types a pilot in the laboratory 
Samples were daily analyzed simultaneously with the initial concentration of arsenic and other metals. The column adsorption experiments were carried out at room temperature. In the survey, the flowing rate is checked and adjusted so that the flow rate does not change based on the data of the volume of output solution changed in range of the rate 2, 5 and 10 $\mathrm{mL} / \mathrm{min}$. The conduct experiments were kept continuously during from 1 day to 30 days, from 7 am to 5 pm for a day. The samples were taken and analyzed pre- and post-treatment on the test kit before analyzing by AAS analysis Shimadzu machines 6300 and 6800 .

\section{RESULTS AND DISCUSSION}

Results of As and heavy metals absorption in authentic water sample: We conducted the preparation of authentic samples having concentration of elements like real sample (wastewater sample of Chemical factory), $\mathrm{pH}$ of sample is also similar to that of real sample ( $\mathrm{pH}$ is 5-6). To have better performance of adsorption column, we increase the $\mathrm{pH}$ of the sample to 7.0-7.5 with bicarbonate salts. Then let the flow pass through the adsorption column; at the first time, the performance is $90-99 \%\left(\mathrm{C}_{\mathrm{in}} / \mathrm{C}_{\text {out }}\right)$; after 3 days the performance decreased from 90 to $70 \%$. After 3 days, the performance is $30 \%$ and at that time the column should be replaced. Thus, based on experiment, the amount of the elements after 3 days may exceed the permission. Therefore, after 3 days, the column material was replaced. The results are shown in Fig. 4.

Fig. 4 showed that the material adsorbed As and heavy metal very effectively, especially in the first 3 days, but the adsorption was decreasing after that. The measured output $\mathrm{pH}$ (6.5-7.0) was not significantly reduced in compare with the input ( $\mathrm{pH}$ was raised to 7.0-7.5). Some metals give the high performance $\mathrm{As}, \mathrm{Mn}, \mathrm{Fe}, \mathrm{Pb}, \mathrm{Cd}$ : even at the 7th day, the performance was still $70-80 \%$. The column adsorption capacity of As and heavy metals at the durations of 1-8 days $(3,6,9,12$, 15,18 and $24 \mathrm{~L}$ ) were shown in the Table-1.

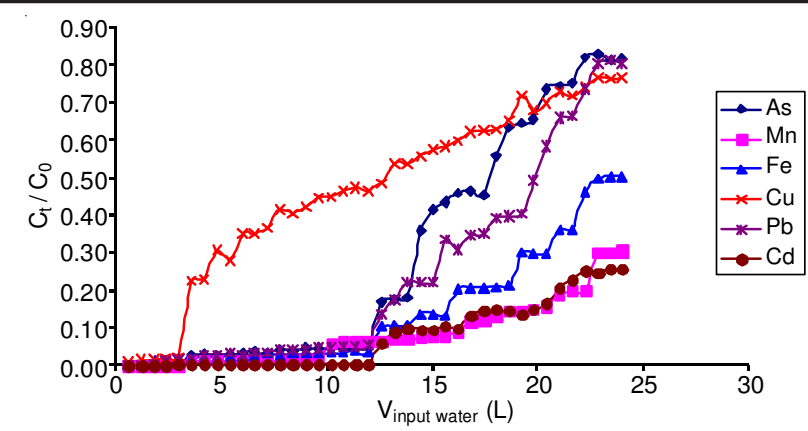

Fig. 4. Graph shows the dependence of $\mathrm{C}_{/} / \mathrm{C}_{0}$ on the input water volume

Adsorption results of arsenic and heavy metals in factory wastewater: The waste sewage water of Lam Thao Superphosphate Factory was taken as the Vienam National Standard No. 6663-6:2008 of water quality and sample taking in river and streams. Measured the concentration in the wastewater pre- and post- treatment by AAS to determine the input and output concentration through the material column as described above. The results are shown below in the Table- 2 .

The results (Table-2) showed that the adsorption capacity of arsenic and heavy metals slightly reduced from the 1 st to 4th day. The material can adsorb arsenic and heavy metal very well. Only with the case of $\mathrm{Cu}$, the capacity dropped rapidly. After 4 days, the column should be replaced. The low cost material of sand and iron powder can adsorb arsenic and heavy metals simultaneously is very prospective to apply onto the reality. In this article, only the adsorption of arsenic and heavy metals is mentioned.

\section{Conclusion}

Arsenic and heavy metals column adsorption of natural material of sand and iron powder shows its high adsorptivity of As $(169.65 \mathrm{mg} / \mathrm{kg})$ and some other metals $\mathrm{Mn}, \mathrm{Fe}, \mathrm{Cu}, \mathrm{Pb}$, Cd (6616.05, 6664.24, 426.07, 143.06 and $120.21 \mathrm{mg} / \mathrm{kg}$, respectively in 4 days of $0.08 \mathrm{~kg}$ material. It has shown the high applicability of sand and iron material in heavy metals treatment by column adsorption.

TABLE-1

ADSORPTION CAPACITY OF As AND HEAVY METALS OF AUTHENTIC SAMPLE

\begin{tabular}{cccccccc}
\hline Day & Output water volume $(\mathrm{L})$ & $\mathrm{L}_{\mathrm{As}}(\mathrm{mg} / \mathrm{kg})$ & $\mathrm{L}_{\mathrm{Mn}}(\mathrm{mg} / \mathrm{kg})$ & $\mathrm{L}_{\mathrm{Fe}}(\mathrm{mg} / \mathrm{kg})$ & $\mathrm{L}_{\mathrm{Cu}}(\mathrm{mg} / \mathrm{kg})$ & $\mathrm{L}_{\mathrm{Pb}}(\mathrm{mg} / \mathrm{kg})$ & $\mathrm{L}_{\mathrm{Cd}}(\mathrm{mg} / \mathrm{kg})$ \\
\hline 1 & 3 & 186.6650 & 6875.6182 & 6694.5089 & 853.3984 & 146.8357 & 111.7299 \\
2 & 6 & 180.3000 & 6797.9773 & 6642.2768 & 567.6563 & 144.6920 & 111.6183 \\
3 & 9 & 178.6000 & 6773.9773 & 6594.5089 & 502.5000 & 142.5725 & 111.4621 \\
4 & 12 & 177.8667 & 6441.0909 & 6563.7054 & 466.0938 & 141.2319 & 111.3917 \\
5 & 15 & 109.6333 & 6336.3864 & 5860.8929 & 371.1523 & 115.7367 & 101.2277 \\
6 & 18 & 83.1667 & 5976.1364 & 5370.0000 & 323.0859 & 90.2114 & 95.1339 \\
7 & 21 & 48.2833 & 5583.8864 & 4325.1116 & 236.4648 & 50.5072 & 89.0625 \\
8 & 24 & 34.5667 & 4788.4091 & 3371.9643 & 204.6094 & 28.9251 & 83.5045 \\
\hline
\end{tabular}

TABLE-2

ADSORPTION CAPACITY OF As AND HEAVY METALS ON THE TREATMENT COLUMN

\begin{tabular}{|c|c|c|c|c|c|c|c|}
\hline Day & Output water volume (L) & $\mathrm{L}_{\mathrm{As}}(\mathrm{mg} / \mathrm{kg})$ & $\mathrm{L}_{\mathrm{Mn}}(\mathrm{mg} / \mathrm{kg})$ & $\mathrm{L}_{\mathrm{Fe}}(\mathrm{mg} / \mathrm{kg})$ & $\mathrm{L}_{\mathrm{Cu}}(\mathrm{mg} / \mathrm{kg})$ & $\mathrm{L}_{\mathrm{Pb}}(\mathrm{mg} / \mathrm{kg})$ & $\mathrm{L}_{\mathrm{Cd}}(\mathrm{mg} / \mathrm{kg})$ \\
\hline 1 & 3 & 186.3833 & 6995.3636 & 6928.9732 & 821.2695 & 149.0399 & 120.5580 \\
\hline 2 & 6 & 185.8500 & 6884.0227 & 6765.1339 & 549.9609 & 146.7935 & 120.5022 \\
\hline 3 & 9 & 185.0000 & 6847.3636 & 6721.8304 & 451.3086 & 144.4384 & 120.3125 \\
\hline 4 & 12 & 169.6500 & 6616.0455 & 6664.2411 & 426.0742 & 143.0616 & 120.2121 \\
\hline 5 & 15 & 161.0667 & 6468.2273 & 6066.3393 & 329.7266 & 116.8780 & 109.8884 \\
\hline 6 & 18 & 86.8500 & 5436.7955 & 5600.0000 & 294.8828 & 91.0628 & 103.3594 \\
\hline 7 & 21 & 45.7333 & 4777.7727 & 4463.7723 & 217.3047 & 52.1800 & 89.8326 \\
\hline
\end{tabular}




\section{REFERENCES}

1. M. Kumaresan and P. Riyazuddin, Curr. Sci., 80, 837 (2001)

2. P.L. Smedley and D.G. Kinniburgh, Appl. Geochem., 17, 517 (2002).

3. M. Berg, H.C. Tran, T.C. Nguyen, H.V. Pham, R. Schertenleib and W. Giger, Environ. Sci. Technol., 35, 2621 (2001).

4. P.H. Viet, T.H.Con, C.T. Ha, H.V. Ha, M. Berg. W. Giger and R. Schertenleib, Invesgitation of Arsenic Removal Technologies for Drinking Water in Vietnam, In Arsenic Exposure and Health Effects V, Published by Elsevier Science, Ch. 35, pp. 459-469 (2003).

5. W. Giger and M. Berg, Neue Zürcher Zeitung, 22, 56 (2001).

6. T. Takamatsu, M. Kawashima and M. Koyama, Water Res., 19, 1029(1985).

7. H.A. Aziz, M.N. Adlan and K.S. Ariffin, Bioresour. Technol., 99, 1578 (2008).
8. M. Berg, H.C. Tran, K.T. Pham, R. Schertenleib and W. Giger, Arsenic Pollution of Water Resources in Vietnam-A Plea for Early Mitigation Actions, Arsenic in Soil and Groundwater Environment Biogeochemical Interactions, Uppsala, Swedwn, pp. 8-9 (2003).

9. M.J. Demarco, A.K. Sengupta and J.E. Greenleaf, Water Res., 37, 164 (2003).

10. D.Q. Hung, O. Nekrassova and R.G. Compton, Talanta, 64, 269 (2004).

11. A. Gomez-Caminero, P. Howe, M. Hughes, E. Kenyon, D.R. Lewis, M. Moore and J. Ng, in eds.: A. Aitio and G. Becking, Arsenic and Arsenic Compounds, Environmental Health Criteria 224, World Health Organization, Geneva (2001).

12. A. Seidel, J.J. Waypa and M. Elimelech, Environ. Eng. Sci., 18, 105 (2001).

13. N. Balasubramanian and K. Madhavan, Chem. Eng. Technol., 24, 519 (2001). 